\title{
Assessing spatial variability of soil water content through Thermal Inertia and NDVI
}

\author{
Pierluigi Claps ${ }^{\mathrm{a}}$, Giovanni Laguardia ${ }^{* \mathrm{~b}}$ \\ ${ }^{a}$ DITIC, Polytechnic of Turin, Turin, Italy \\ ${ }^{\mathrm{b}}$ DIFA-CIMA, University of Basilicata, Potenza, Italy
}

\begin{abstract}
AVHRR (Advanced Very High Resolution Radiometer on board NOAA satellites) data are considered here to evaluate the possibility of using the surface temperature as an indicator of the soil/canopy water content at the short time-scale. This is obtained by means of an indirect approach based on a simplified soil-atmosphere energy balance. The techniques provide sufficiently detailed coverage of the processes in terms of the time and spatial scale with respect to hydrological applications. Two different approaches have been tried: the first based on thermal inertia measurements (Xue \& Cracknell, 1995) ${ }^{1}$ through ATI (Apparent Thermal Inertia), the second based on surface temperature (LST) and vegetation indices (NDVI), with the TVDI (Temperature Vegetation Dryness Index) suggested by Sandholt et al. $(2002)^{2}$. Both techniques were used in detecting moist areas in a single image (or day/night images), and in multitemporal multitemporal applications. In particular, a new cloud detection algorithm, based on the bimodal frequency distribution of the infrared brightness temperatures (Ch 5 AVHRR) when clouds affect the image, has been proposed for ATI. As regards TVDI, a modified technique has been proposed for fixing the warm edge of the triangle based on the detection of the extreme dryness conditions on a monthly basis. The modified TVDI has been tested in comparison with an antecedent precipitation index (API) for moisture detection in single images. The substitution of day/night land surface temperature differences instead of noon temperatures in the "triangle method" has been also tested with good results in the multitemporal approach. Application of the proposed techniques can allow one to track the evolution of soil moisture in space and time and to improve the knowledge on the relationship between vegetation (NDVI) and soil moisture dynamics.
\end{abstract}

Keywords: soil moisture, thermal inertia, NDVI

\section{INTRODUCTION}

The knowledge of the spatio-temporal soil moisture dynamics is of great interest in flood hydrology i.e. for drought monitoring (McVicar and Jupp, 1998) ${ }^{3}$ or for the management of water resources in wide irrigation schemes (Kite and Droogers, 2000) ${ }^{4}$. The expense for ground measurements and their low representativity due to their high spatial and temporal variability leave much space to remote sensing applications, characterized by high temporal frequency and synoptic spatial coverage, especially considering the development of sensors able to explore wider and wider regions of the electromagnetic spectrum.

In the field of soil moisture detection from space, most efforts are concentrated on exploiting the potential of the microwaves methods (e.g. Engman and Chauhan, 1995 ; Schmugge, 1998 ${ }^{6}$ ). However, a still poor spatial resolution limits current applicability of passive microwaves, while active microwave data are only available at low temporal frequency and at high costs. These factors constitute major constraints in the practical application of those data for operative hydrological purposes. For this reason, other "indirect" techniques for soil water evaluation based on radiometric measures in the optical range are being actively considered, mainly as part of soil-vegetation-atmosphere transfer models (Castelli et al., 1999) ${ }^{7}$, which benefit of remote measurements of the thermal properties of the soil top layers. A number of approaches have been proposed for indirect evaluation of soil moisture through radiometric data, essentially based on measurements of surface temperature, evaluated in the thermal infrared region (e.g. Price, 1980) ${ }^{8}$, possibly integrated by vegetation information (Carlson et al., 1995) ${ }^{9}$ retrieved in the visible channels. These methods,

*laguardia@unibas.it; phone +39 (0)971 205359; fax +39 (0)971 205139 
mainly built upon AVHRR data, can be transposed on the new generation sensors, such as MODIS (Moderate Resolution Imaging Spectroradiometer), which present improved spatial and radiometric resolution.

One of the key points we consider in the analysis of the existing and proposed models is the quantity and quality of ground data actually available for the application of methodologies. The application of Remote Sensing techniques on a regional scale has to face a limited availability of data on variables, such as air wetness, wind velocity, soil temperature, often required for the ultimate evaluation of soil moisture. Our specific interest here is related to the re-evaluation of the role of "stand alone" indices of soil moisture in the context of a long-term and wide-area evaluation of the variability of soil/canopy moisture content to be used in regional analysis.

\section{METHODOLOGY}

In the field of soil moisture detection based on thermal infrared and visible measurements, the so called indirect approach, two different ways have been tried: the first based on thermal inertia measurements (Xue \& Cracknell, 1995) ${ }^{1}$ through ATI (Apparent Thermal Inertia) (Tramutoli et al., 2000) ${ }^{10}$; the second based on surface temperature (LST) and vegetation indices (NDVI), well known as "triangle method" (Carlson et al., 1995) ${ }^{9}$ with the TVDI (Temperature Vegetation Dryness Index) suggested by Sandholt et al. (2002) ${ }^{2}$. A brief description of these methods follows.

\subsection{METHODS BASED ON THERMAL INERTIA}

The starting point of the history of thermal inertia as an index of soil moisture coincides with the ending point in the Price $(1985)^{11}$ paper, related to the use of thermal inertia for discrimination of geologic materials. Along with the significance of the topographic relief, soil moisture was in fact the main factor affecting the thermal inertia information for geological classification. This side effect is so significant to lead Price suggesting to give up with the use of thermal inertia for the main purpose of the HCMM NASA mission (NASA, 1978) ${ }^{12}$. Problems and caveats referred to the use of the remotely-sensed thermal inertia were highlighted by Carlson $(1986)^{13}$, who pictured the useful properties of the physical parameter as well.

Thermal Inertia (TI) is an intrinsic property of every material, function of its conductibility (K), density (r) and specific heat capacity (c), according to the following relation:

$$
T I=\sqrt{\rho K c} .
$$

It represents the measure of the material resistance to the temperature changes imposed by the outside, meaning that, for a given incoming heat flux, the variation of soil temperature is inversely proportional to its thermal inertia, which is in turn influenced from soil water because of its high specific heat. Therefore it is possible to try to estimate soil water content measuring the surface temperature diurnal cycle. Water bodies, having a TI higher than the dry and wet soils, show the lowest fluctuation of temperature in daytime.

Remote sensing techniques do not allow the directly measurement of actual thermal inertia. In the specific literature there are models that, starting from remotely sensed data, are able to evaluate the real parameter but they typically need ancillary ground data, which could be not always available (Cracknell and Xue, 1996) ${ }^{14}$. A model for the evaluation of thermal inertia based only on satellite data has been proposed by Sobrino et al. $(1998)^{15}$, but it requires the availability of three (night/day/night) images, which is difficult to obtain for the problems related to clouds. A simple model is that of Watson $(1971)^{16}$, based on the assumption that the sun produces a periodic heating of the terrestrial surface and the losses of heat from the ground are entirely caused by radiative transfers. If $\mathrm{S}$ is the solar energy incident on a surface of albedo A, it results:

$$
S=A \cdot S+(1-A) \cdot S .
$$

The quantity of heat absorbed by the surface determines an increase of the surface temperature. The amount of such increase $(\Delta \mathrm{T})$ depends on thermal inertia. Introducing ATI (Apparent TI) (NASA, 1978 ${ }^{12}$; Price, 1980 ${ }^{8}$ ) as an 
approximate thermal inertia value and considering an area with uniform solar energy, we obtain the following relationship:

$$
A T I=\frac{1-A}{\Delta T}
$$

where $\Delta \mathrm{T}$ can be assumed as the difference between the maximum ( $\left.\mathrm{T}_{\max }\right)$ and the minimum $\left(\mathrm{T}_{\min }\right)$ value that the surface temperature assumes during the diurnal cycle. As such, ATI has dimension of $\mathrm{K}^{-1}$. ATI has been validated on the study area in a previous work (Tramutoli et al., 2000) ${ }^{10}$ in an application in a short temporal window. For multitemporal analyses the variability of the energy forcing, at least on a seasonal basis, can not be ignored. For more accurate results ancillary data are needed.

Particular attention must be paid in cloud detection. This procedure has a key role especially when working with coupled day-night images. Threshold tests in the visible and infrared channels have been applied. In particular, when working on IR channels, the markedly bimodal frequency distribution of brightness temperatures due to the presence in the images of two different phenomena, such as land surface and clouds, gives a valuable help in the choice of the threshold on a seasonal basis (see Figure 1). Statistical filters, such as working with median values, have been applied when extracting a representative value from a set of pixels.
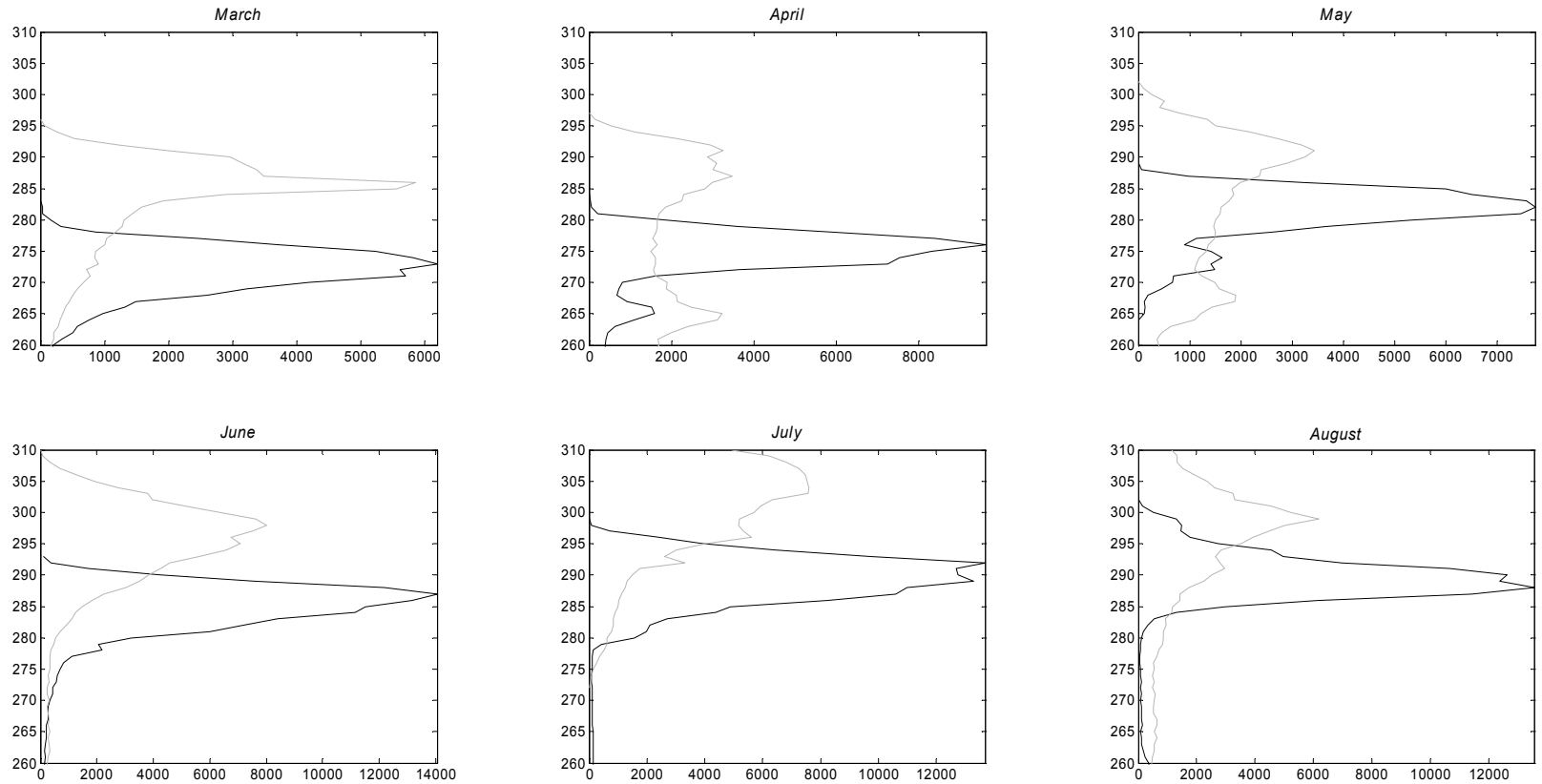

Figure 1: Frequency distribution of Ch5 AVHRR brightness temperatures determined on a monthly basis. The black line represents nighttime images, the gray one daytime images.

\subsection{THE TRIANGLE METHOD}

Land surface temperature is determined by the partitioning between latent and sensible heat fluxes. It allows trying to determine soil moisture, given the energy forcing, measuring surface temperatures. Vegetation plays an important role for its capability of extracting water from terrain layers not involved in evaporation. On this basis, Carlson et al. (1995) ${ }^{9}$ created the "triangle method". This method inherits its name by the particular shape that the measurements of land surface temperature (LST) and normalized difference vegetation index (NDVI) assume in a scatterplot (see Figure 2).

The edges in the scatterplot represent the LST range of variation. The upper limit (warm edge) represents soils with no available moisture, the lower one (wet edge) very moist soils. Sandholt $(2002)^{2}$ suggests to evaluate an index of soil moisture by means of the ratio between the distance of a point respect to the wet edge (A in 
Figure 2 and Figure 3) and the distance between the edges (B) for the given value of NDVI:

$$
T V D I=\frac{A}{B} .
$$

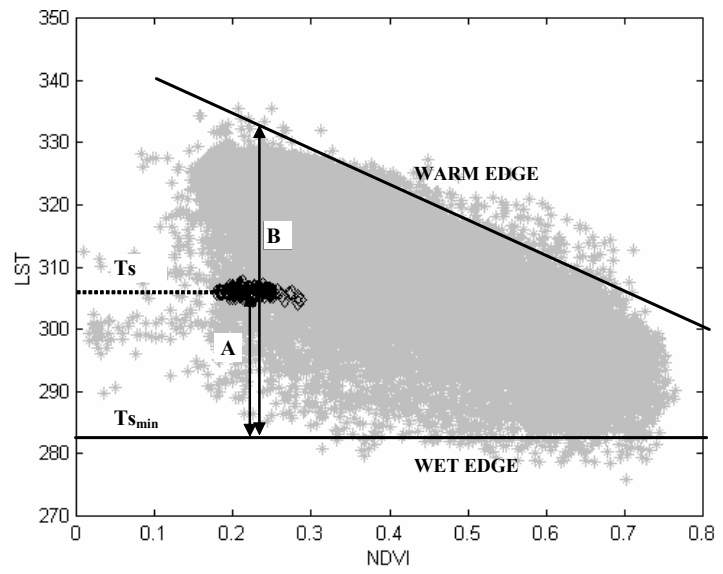

Figure 2: NDVI-LST scatterplot.

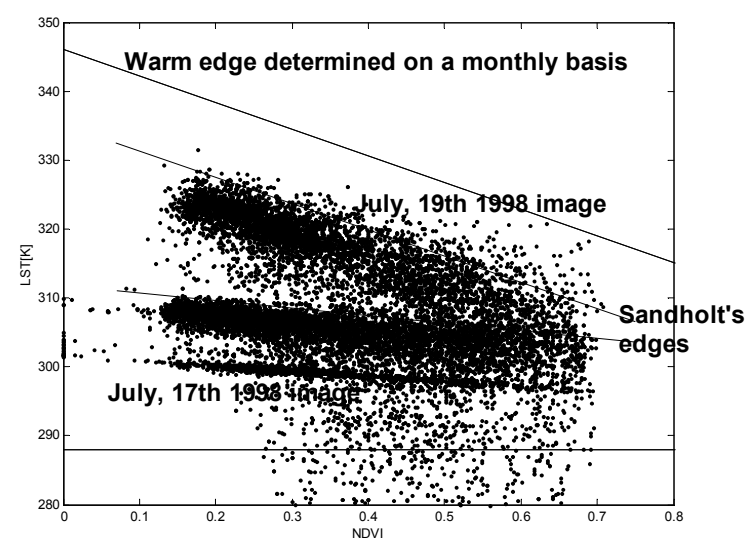

Figure 4: July, 17th and 19th 1998 images plotted in the NDVILST space. In July, 16th a rainfall event occurred on the study area. The determination of the warm edge as suggested by Sandholt et al. (2002) forces TVDI to assume too high values. Working with the warm edge determined on a monthly basis, the modified TVDI increases in a continuous way after the rainfall event.

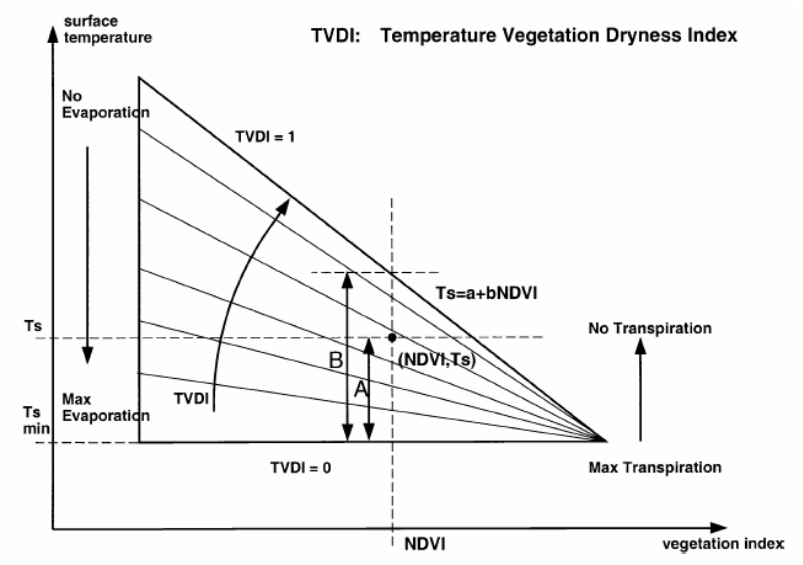

Figure 3: TVDI in the NDVI-LST space (adapted from Sandholt, 2002).

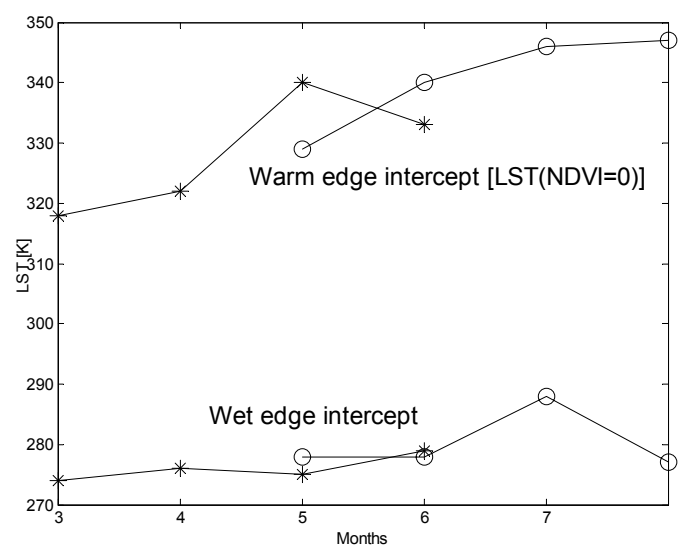

Figure 5: Intercepts of the warm edge and wet edge determined on a monthly basis with the LST axis for the years 1998 (circle) and 1999 (asterisc).

The Sandholt's Temperature Vegetation Dryness Index (TVDI), as suggested by its name, is a no-moisture index, reaching its maximum (TVDI=1) at the warm edge. The methodology for the determination of TVDI for multitemporal applications is reported in Sandholt et al. (2002). In the same work and in a subsequent one (Andersen et al., 2002) ${ }^{17}$ TVDI has been tested by comparison with MIKE-SHE model outputs. TVDI well represents soil moisture spatial variability; on the other hand it seems suffering in reproducing temporal dynamics. In the development of the present work we found a similar behaviour when working as suggested in Sandholt et al. (2002) ${ }^{2}$. In particular, the determination of the warm edge on a daily basis seems to force the TVDI in assuming too high values (see Figure 4). For this reason, considering that in the short term and especially in the absence of important perturbations on the study area, 
essential condition for the availability of cloud free satellite data, that means the images can be considered homogeneous, the determination of the edges on a monthly basis has been tried (see Figure 5).

\subsection{A PROPOSAL FOR THE MULTITEMPORAL SOIL MOISTURE MAPPING: THE COMBINATION OF TRIANGLE METHOD AND THERMAL INERTIA}

When working with thermal inertia we found significant relations between ATI and vegetation. Well vegetated areas presented higher values of ATI and a lower recession rate of soil moisture (Tramutoli et al., 2000) ${ }^{10}$. For this reason we put great emphasis on triangle method: vegetation has a key role in surface energy balance and soil moisture. Besides, working on the estimation on a physical basis of the parameters of a theoretical probabilistic model proposed by Iacobellis and Fiorentino $(2000)^{18}$, a strong relationship was found between the hydrologic losses during flood events $\left(\mathrm{f}_{\mathrm{A}}\right)$ and NDVI, as representative of the climate and of the characteristic conditions of soil moisture of a basin (Fiorentino et al., 2002) ${ }^{19}$.

On the other hand, when working with the "absolute" values of land surface temperature, as in the triangle method, it can be difficult to face to errors in temperature estimates or to extend the analyses in wider temporal intervals for the observed seasonal variability of the edges of the triangle. For those reasons it should be useful to work with relative values, as the day-night difference of the surface temperatures (DT). When substituting DT to surface temperatures in the NDVI-T space, the plot assumes a shape very similar to what obtained in triangle method. It is still possible to evaluate an index of soil moisture similar to TVDI, that we will call DTVDI, which has been tested by comparison with an index of soil moisture based on the antecedent precipitation. The determination of the warm edge on an annual basis has been tried. DTVDI is resulted to be rather insensitive to seasonality in DT variations. Also the NDVI variations related to vegetation phenological rhythms are well interpreted. Therefore, DTVDI looked particularly well fitted for multitemporal applications.

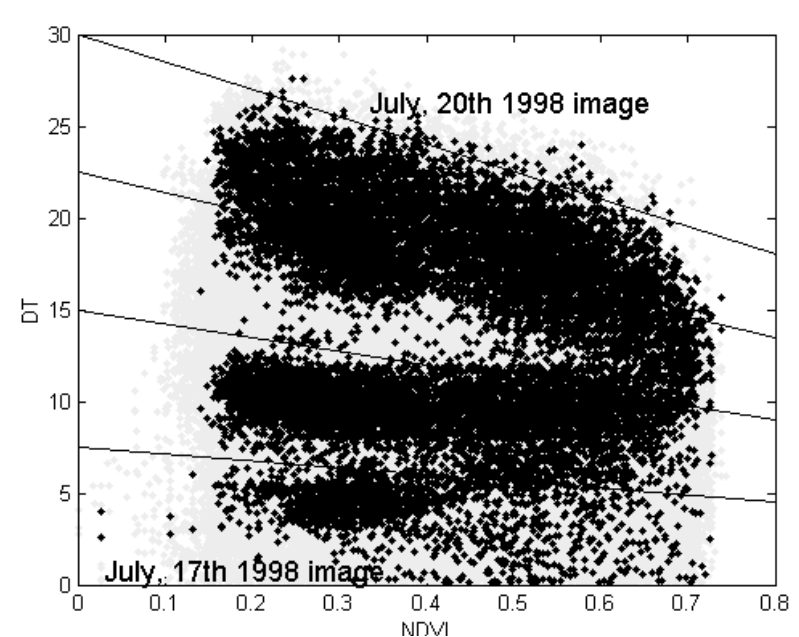

Figure 6: July, 17th and 20th 1998 images plotted in the NDVILST space. In gray the scatterplot for the entire dataset.

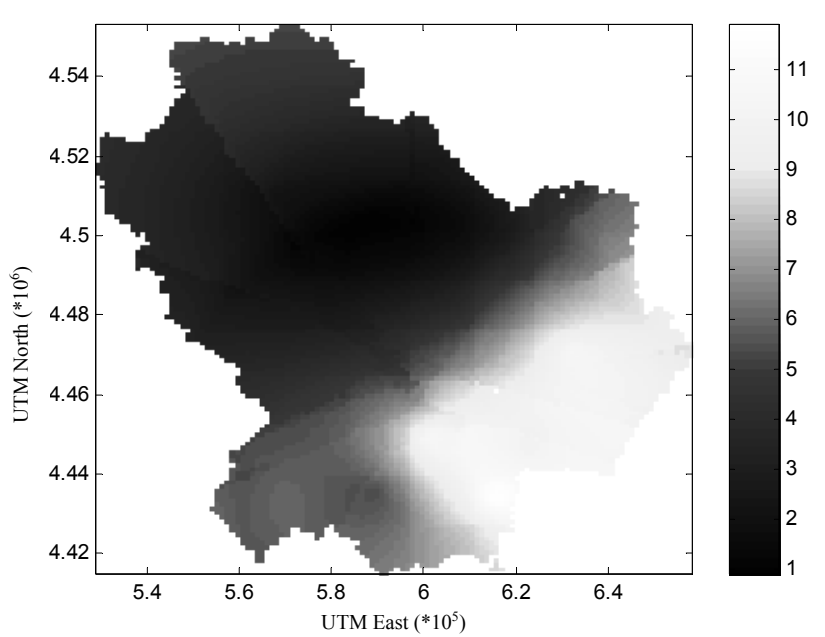

Figure 7: Rainfall field for the 16th of July, 1998.

\section{APPLICATION}

In this section the capabilities of the modified TVDI and the DTVDI in representing spatial and temporal variability of soil moisture will be evaluated.

The response of the indices to rainfall will be evaluated in terms of temporal dynamics working on squared areas centred on the meteorological stations; the spatial response to rainfall will be evaluated using rainfall fields reconstructed by the 
gauged points via kriging. When working on the squares, median values and standard deviation of the indices and the percent of pixels detected as not cloudy have been extracted for a better identification of residual cloud effects.

\subsection{STUDY AREA AND AVAILABLE DATASETS}

The Basilicata region, Southern Italy, has an area of about $10.000 \mathrm{~km}^{2}$. It is characterized by a complex orography (see Figure 8). Annual rainfall ranges from $2000 \mathrm{~mm}$ in the S-W to $400 \mathrm{~mm}$ in the N-E, determining a very variable climate, going from humid to arid, as described by the Budyko Aridity index (Figure 9).

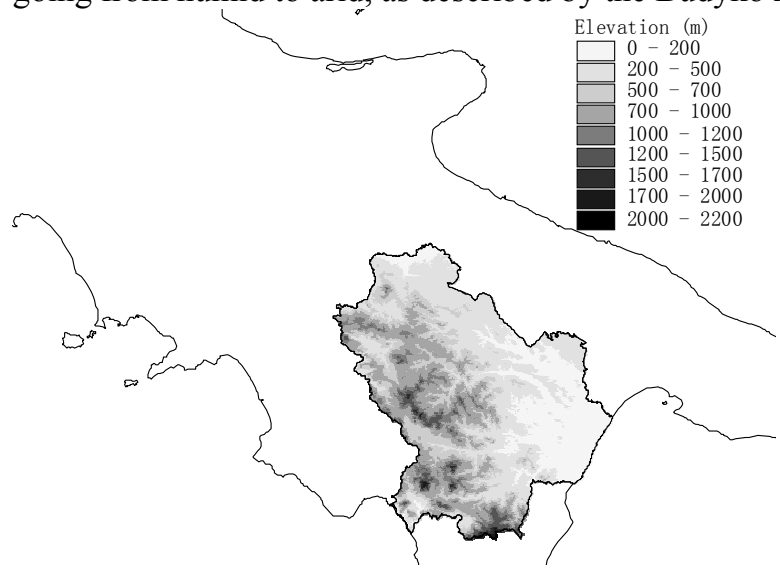

Figure 8: Orography of Basilicata region.

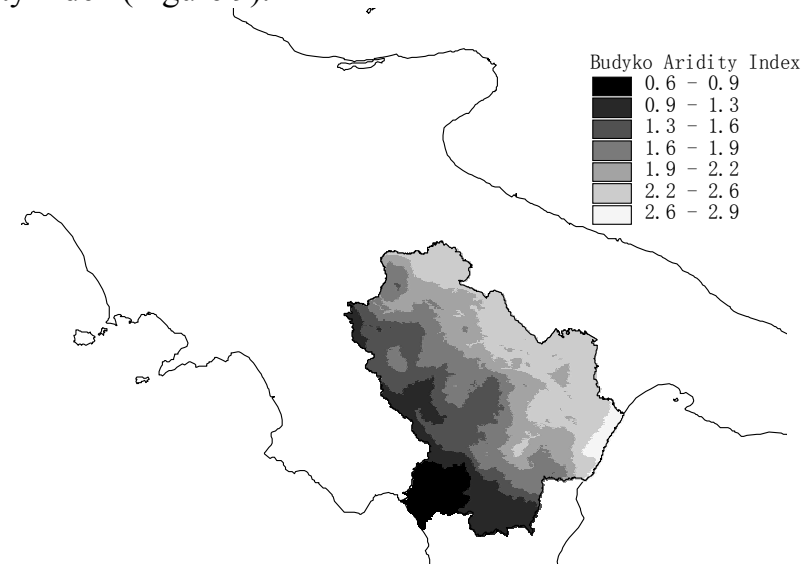

Figure 9: Budyko Aridity Index: $\mathrm{BAI}=\mathrm{Rn} /(\lambda \mathrm{P})$.

The work is based on Advanced Very High Resolution Radiometer (AVHRR, on board of NOAA satellites) imagery extracted from the historical image archive of the IMAA (Institute of Methodologies of Environmental Analysis) of the National Research Council. Satellite images have been pre-processed, selected and analyzed according to the scheme described in Tramutoli et al. (2000) ${ }^{10}$. In Table 1 the consistency of the satellite dataset for this study is reported.

\begin{tabular}{|c|c|c|c|c|c|c|c|c|}
\hline \multirow[t]{2}{*}{ Day } & \multicolumn{4}{|c|}{1998} & \multicolumn{4}{|c|}{1999} \\
\hline & May & June & July & August & March & April & May & June \\
\hline 1 & & & & $\mathrm{D} / \mathrm{N}$ & $\mathrm{D} / \mathrm{N}$ & $\mathrm{D} / \mathrm{N}$ & & \\
\hline 2 & & & & & & $\mathrm{D} / \mathrm{N}$ & & \\
\hline 3 & & $\mathrm{D} / \mathrm{N}$ & $\mathrm{D} / \mathrm{N}$ & & & & & \\
\hline 4 & & $\mathrm{D} / \mathrm{N}$ & & $\mathrm{D} / \mathrm{N}$ & & $\mathrm{D} / \mathrm{N}$ & & \\
\hline 5 & & & $\mathrm{D} / \mathrm{N}$ & & & $\mathrm{D} / \mathrm{N}$ & & \\
\hline 6 & & & $\mathrm{D} / \mathrm{N}$ & & & $\mathrm{D} / \mathrm{N}$ & & \\
\hline 7 & & & & $\mathrm{D} / \mathrm{N}$ & & & & \\
\hline 8 & & & & & & & $\mathrm{D} / \mathrm{N}$ & \\
\hline 9 & & & & & $\mathrm{D} / \mathrm{N}$ & & $\mathrm{D} / \mathrm{N}$ & \\
\hline 10 & & & $\mathrm{D} / \mathrm{N}$ & & & & $\mathrm{D} / \mathrm{N}$ & \\
\hline 11 & & $\mathrm{D} / \mathrm{N}$ & & & $\mathrm{D} / \mathrm{N}$ & & & \\
\hline 12 & & & & $\mathrm{D} / \mathrm{N}$ & $\mathrm{D} / \mathrm{N}$ & & & $\mathrm{D} / \mathrm{N}$ \\
\hline 13 & & & $\mathrm{D} / \mathrm{N}$ & $\mathrm{D} / \mathrm{N}$ & & $\mathrm{D} / \mathrm{N}$ & $\mathrm{D} / \mathrm{N}$ & \\
\hline 14 & & & & & & $\mathrm{D} / \mathrm{N}$ & & $\mathrm{D} / \mathrm{N}$ \\
\hline 15 & & & & $\mathrm{D} / \mathrm{N}$ & & & & $\mathrm{D} / \mathrm{N}$ \\
\hline 16 & & & & $\mathrm{D} / \mathrm{N}$ & & & & \\
\hline 17 & & & $\mathrm{D} / \mathrm{N}$ & $\mathrm{D} / \mathrm{N}$ & & & & \\
\hline 18 & & $\mathrm{D} / \mathrm{N}$ & & $\mathrm{D} / \mathrm{N}$ & & & & \\
\hline 19 & & $\mathrm{D} / \mathrm{N}$ & $\mathrm{D} / \mathrm{N}$ & & & $\mathrm{D} / \mathrm{N}$ & & \\
\hline 20 & & $\mathrm{D} / \mathrm{N}$ & $\mathrm{D} / \mathrm{N}$ & & & $\mathrm{D} / \mathrm{N}$ & & \\
\hline 21 & $\mathrm{D} / \mathrm{N}$ & $\mathrm{D} / \mathrm{N}$ & $\mathrm{D} / \mathrm{N}$ & $\mathrm{D} / \mathrm{N}$ & & & & $\mathrm{D} / \mathrm{N}$ \\
\hline 22 & & $\mathrm{D} / \mathrm{N}$ & & & & & & $\mathrm{D} / \mathrm{N}$ \\
\hline 23 & & $\mathrm{D} / \mathrm{N}$ & $\mathrm{D} / \mathrm{N}$ & & & & & $\mathrm{D} / \mathrm{N}$ \\
\hline 24 & $\mathrm{D} / \mathrm{N}$ & $\mathrm{D} / \mathrm{N}$ & $\mathrm{D} / \mathrm{N}$ & & $\mathrm{D} / \mathrm{N}$ & & & $\mathrm{D} / \mathrm{N}$ \\
\hline 25 & & $\mathrm{D} / \mathrm{N}$ & & & & $\mathrm{D} / \mathrm{N}$ & $\mathrm{D} / \mathrm{N}$ & \\
\hline 26 & $\mathrm{D} / \mathrm{N}$ & & $\mathrm{D} / \mathrm{N}$ & $\mathrm{D} / \mathrm{N}$ & & $\mathrm{D} / \mathrm{N}$ & & $\mathrm{D} / \mathrm{N}$ \\
\hline 27 & $\mathrm{D} / \mathrm{N}$ & $\mathrm{D} / \mathrm{N}$ & $\mathrm{D} / \mathrm{N}$ & $\mathrm{D} / \mathrm{N}$ & $\mathrm{D} / \mathrm{N}$ & & $\mathrm{D} / \mathrm{N}$ & $\mathrm{D} / \mathrm{N}$ \\
\hline 28 & $\mathrm{D} / \mathrm{N}$ & $\mathrm{D} / \mathrm{N}$ & $\mathrm{D} / \mathrm{N}$ & & & & $\mathrm{D} / \mathrm{N}$ & \\
\hline 29 & $\mathrm{D}$ & $\mathrm{D} / \mathrm{N}$ & $\mathrm{D} / \mathrm{N}$ & & & & $\mathrm{D} / \mathrm{N}$ & \\
\hline 30 & $\mathrm{D} / \mathrm{N}$ & & & & & & $\mathrm{D} / \mathrm{N}$ & \\
\hline 31 & $\mathrm{D} / \mathrm{N}$ & & $\mathrm{D} / \mathrm{N}$ & & & & & \\
\hline
\end{tabular}

Table 1: AVHRR images dataset. D/N represents the availability of the images for the day/night satellite overpass. 
Rainfall and air temperature measurements from 80 stations of the Hydrographical National Survey and of the Regional Agency for Development and Innovation in Agriculture (ALSIA) are available for 1998 and 1999. We found a lack of ground data in the northern part of the study area, which gave some troubles in rainfall mapping in that area.

\subsection{TVDI RESPONSE TO RAINFALL}

In section 2.2 a modified method for the determination of TVDI has been suggested. The modified TVDI showed a reasonable temporal response to rainfall (see Figure 10). Working with the check points of the percent of cloudless pixels and the confidence intervals, it is particularly simple to recognize erroneous TVDI estimates. Only in some cases (e.g. days 170 and 171) it seems that TVDI is underestimated, but looking to the satellite images in the period and to air temperature measurements, it is evident that some perturbing effects occurred, such as the passage of clouds before the satellite overpass and a sequence of cold days, with a reduction in surface temperatures.

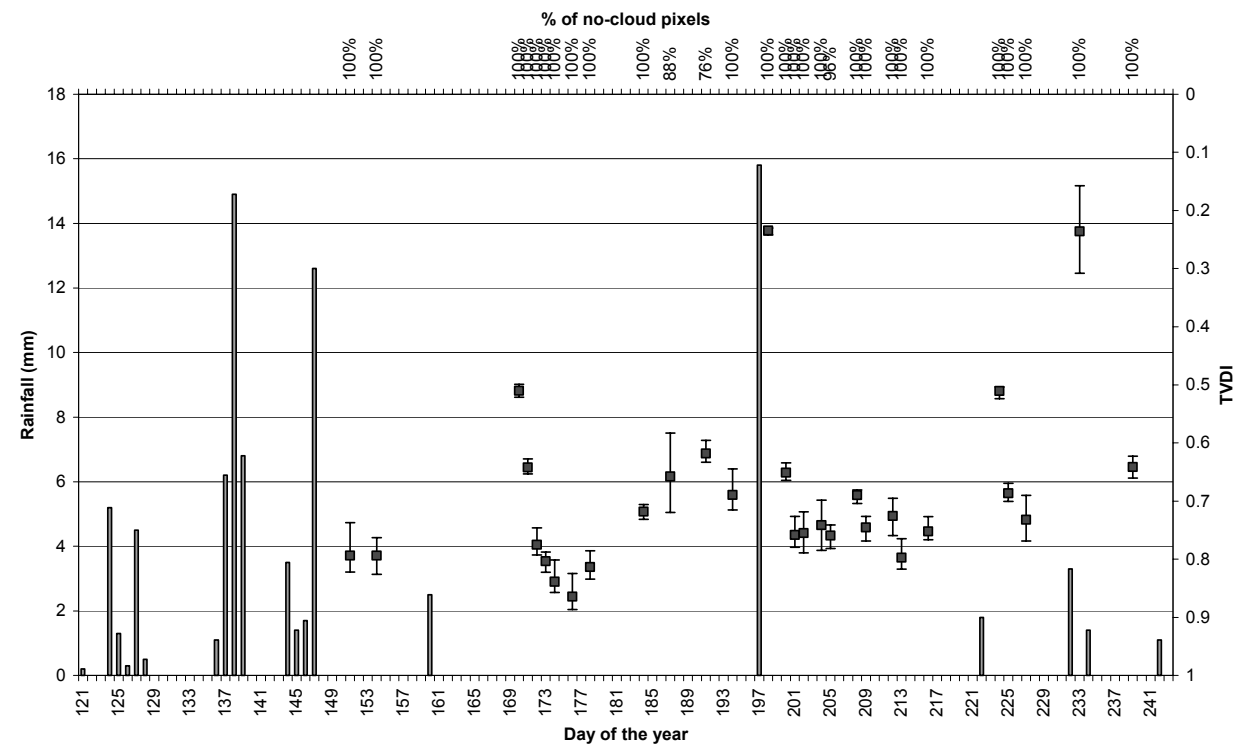

Figure 10: TVDI-rainfall comparison for the Pisticci station for the period May-August 1998.On the bottom axis the day of the year is reported; on the left the rainfall (mm); on the right the TVDI; on the upper the percent of cloudless pixels in the square area around the gauged station.
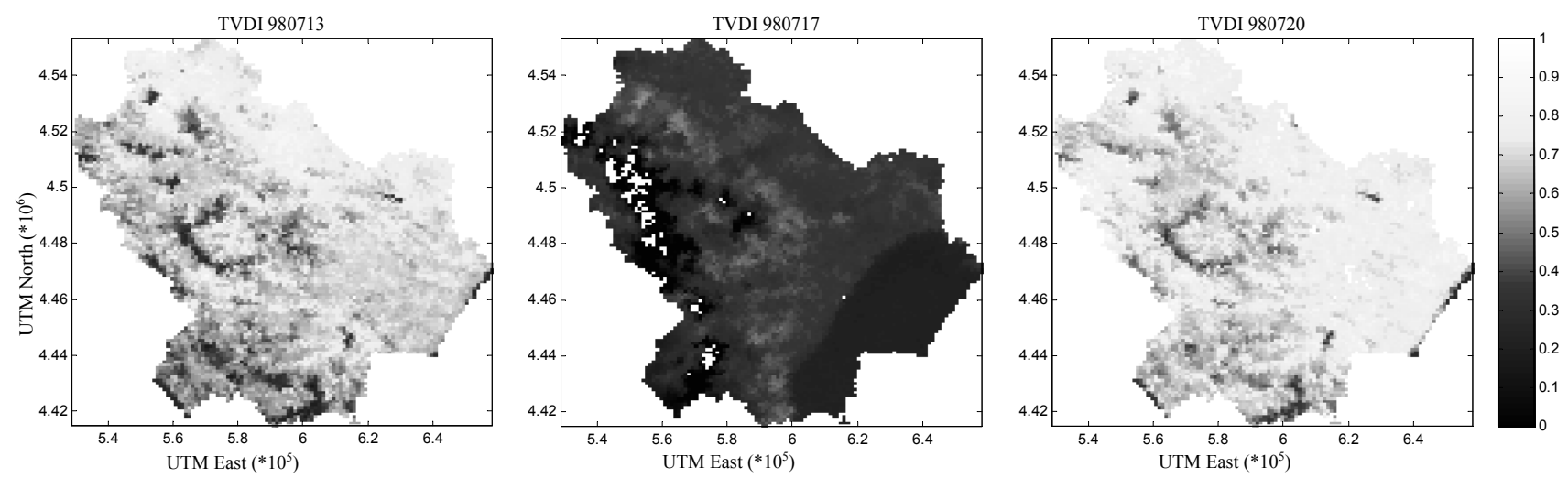

Figure 11: TVDI spatial variability. The first map is relative to $13^{\text {th }}$ of July, 1998, three days before the figure 7 rainfall event; the second to the $17^{\text {th }}$ of July, one day after the rainfall event, with an evident correlation with the rainfall field; the third to the $20^{\text {th }}$ of July, four days after the event. 
TVDI spatial response to rainfall has been evaluated. The TVDI map of the $17^{\text {th }}$ of July, 1998 (the central map in Figure 11) shows a strong correlation with the rainfall map of the $16^{\text {th }}$ of July event (see Figure 7). In particular it is evident the different response of the index to different amounts of rainfall. Four days after the rainfall event the TVDI map is very similar to that measured in the $13^{\text {th }}$ of July, due to the high recession rate of the observed soil layer.

The three TVDI maps in Figure 11 show a spatial organisation of moisture that can be referred to the local control of the preferred states suggested by Grayson et al.(1997) ${ }^{20}$. In particular, it is not possible to observe the spatial redistribution of moisture due to lateral flow (the nonlocal control) after the rainfall event, while it is evident the local control, with the vegetation (as observed through NDVI) having a strong role: the roots of the forests allow to transpirate amounts of water from soil layers not involved in evaporation in barren areas.

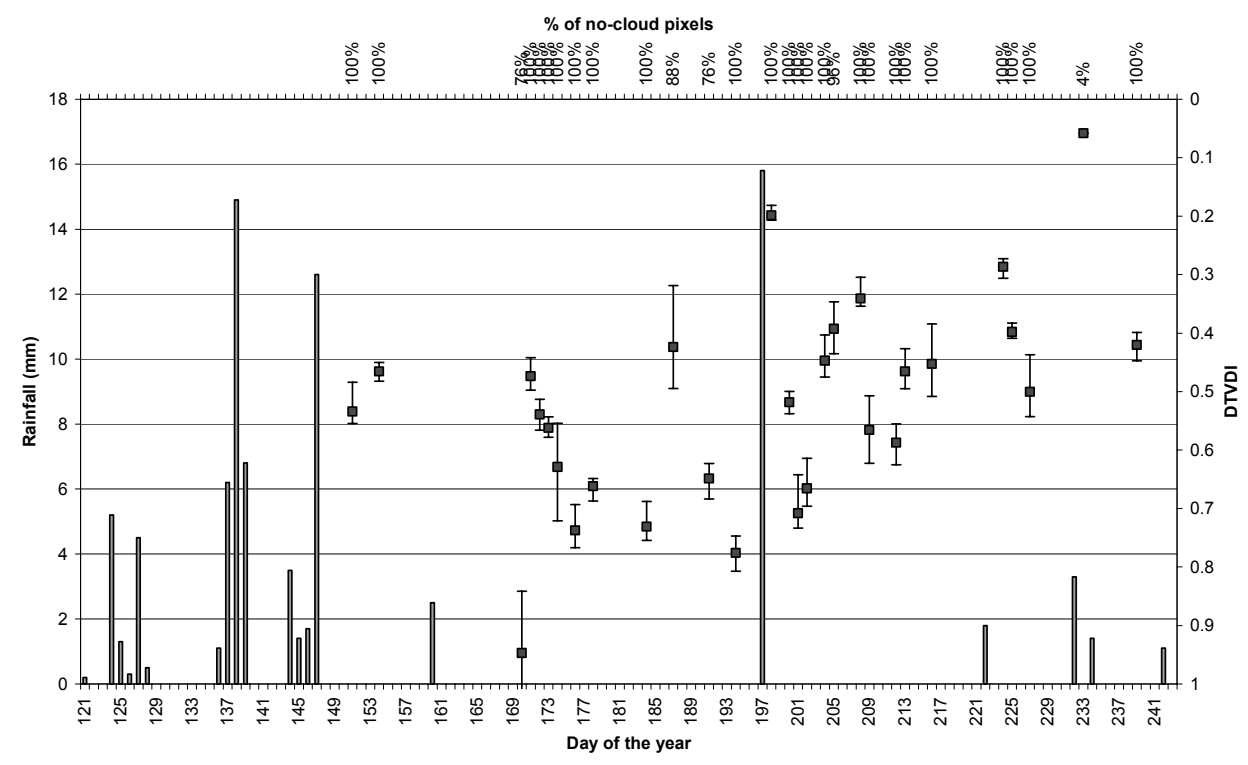

Figure 12: DTVDI-rainfall comparison for the Pisticci station for the period May-August 1998.
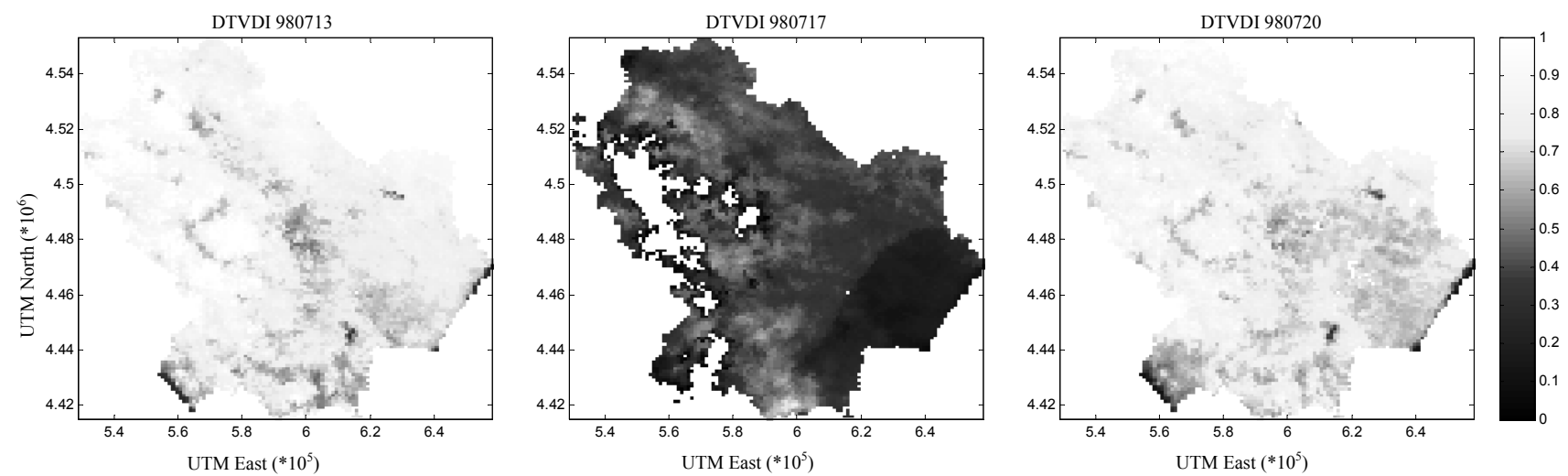

Figure 13: DTVDI spatial variability. The first map is relative to $13^{\text {th }}$ of July, 1998, three days before the figure 8 rainfall event; the second to the $17^{\text {th }}$ of July, one day after the rainfall event, with an evident correlation between DTVDI and the rainfall field; the third to the $20^{\text {th }}$ of July, four days after the event.

\subsection{DTVDI RESPONSE TO RAINFALL}

DTVDI has been proposed to overpass the seasonality problems related to TVDI. However it is necessary to work with day/night imagery. This leads to a strong reduction in the available datasets for long term analyses due to difficulties in finding two subsequent clear sky images especially in rainy seasons, but also to problems in the detection of error 
affected data. The last issue is evident in Figure 12: in the period between the days 204 and 217 DTVDI has a strong temporal instability despite the absence of rainfall and clouds. Besides, facing to noisy results is expected when working with very simple models and without ancillary data.As TVDI, DTVDI shows good capabilities in reproducing the spatial variability of soil moisture. Figures 10 and 12 are very similar despite a wider cloud-masked area in the $17^{\text {th }}$ of July map of DTVDI.

\section{CONCLUSIONS}

In this work indirect approaches to soil moisture retrieval without any ancillary data requirement has been presented. The goal was the determination of indices to be used in multitemporal applications for the characterization of the spacetime soil and canopy moisture evolution, for possible use in regional analysis of floods and droughts.

Modifications and improvement have been proposed to existing techniques, such as those based on Apparent Thermal Inertia and on the combined use of surface soil temperature and NDVI. An improved cloud detection algorithm has been devised, even though the indices are still suffering some atmospheric effects on the measurement of the brightness temperature, particularly in the treatment of day/night image pairs. As a promising step forward in soil moisture tracking, a combination of difference temperature and NDVI has been proposed for operational use with multitemporal images. The proposed techniques have been validated with antecedent precipitation indices on a $10000 \mathrm{~km}^{2}$ area in Southern Italy.

\section{ACKNOWLEDGMENTS}

This work has been carried out within the framework of ICLISV project, funded by MIUR (Cofin 2001). Funding support from CNR-GNDCI is also acknowledged.

\section{REFERENCES}

1. Y. Xue, A. Cracknell, "Advanced thermal inertia modeling”, International Journal of Remote Sensing, 16(3), 431, 1995.

2. I. Sandholt, K. Rasmussen, J. Andersen, "A simple interpretation of the surface temperature-vegetation index space for assessment of surface moisture status", Remote Sensing of Environment, 79, 213-224, 2002.

3. T.R. McVicar, D.L.B. Jupp, "The current and potential operational uses of remote sensing to aid decisions on drought exceptional circumstances in Australia: a review”, Agricultural Systems, 57(3), 399-468, 1998.

4. G. Kite, P. Droogers, "Comparing evapotranspiration estimates from satellites, hydrological models and field data", Journal of Hydrology, 229, 3-18, 2000.

5. E.T. Engman, V. Chauhan, "Status of microwave soil moisture measurements with remote sensing", Remote Sensing of the Environment, 51(1), 189-198, 1995.

6. T.J. Schmugge, “Applications of Passive Microwave Observations of Surface Soil Moisture”, Journal of Hydrology, 212-213, 188-200, 1998.

7. F. Castelli, D. Entekhabi, E. Caporali, "Estimation of surface heat flux and an index of soil misture using adjointstate surface energy balance", Water Resources Research, 35(10), 3115-3125, 1999.

8. J.C. Price, "The potential of remotely sensed thermal infrared data to infer surface soil moisture and evaporation", Water Resources Research, 16 (4), 787 -795, 1980.

9. T.N. Carlson, R.R. Gillies, T.J. Schmugge, "An Interpretation of methodologies for indirect measurement of soil water content", Agricultural and forest meteorology, 77, 191-205, 1995.

10. V. Tramutoli, P. Claps, M. Marella, N. Pergola, C. Sileo, "Feasibility of hydrological application of thermal inertia from remote sensing", Proc. of the 2nd Plinius Conference on Mediterranean Storms, Siena, Italy, 2000.

11. J.C. Price, "On the analysis of thermal infrared: the limited utility of Apparent thermal inertia", Remote Sensing of Environment, 18, 59-73, 1985. 
12. NASA, Heat Capacity Mapping Mission User's Guide, NASA, Goddard Space Flight Center, Greenbelt, Maryland, 1978.

13. T.N. Carlson, "Regional-scale estimates of surface moisture availability and thermal inertia using remote thermal measurements", Remote Sensing Reviews, 1, 197-247, 1986.

14. A. Cracknell, Y. Xue, "Thermal inertia determination from space - a tutorial review", International Journal of Remote Sensing, 17(3), 431-461, 1996.

15. J.A. Sobrino, M.H. El Kharraz, J. Cuenca, N. Raissouni, "Thermal inertia mapping from NOAA-AVHRR data", Advances in Space Research, 22(5), 655-667,1998.

16. K. Watson, A computer program of thermal modelling for interpretation of infrared images. U.S. Geological Survey Report, P.B. Washington D.C., 1971.

17. J. Andersen, I. Sandholt, K.H. Jensen, J.C. Refsgaard, H. Gupta, "Perspectives in using a remotely sensed dryness index in distributed hydrological models at the river-basin scale", Hydrological Processes, 16, 2973-2987, 2002.

18. V. Iacobellis, M. Fiorentino, "Derived distribution of floods based on the concept of partial area coverage with a climatic appeal”, Water Resources Research, 36(2), 469-482, 2000.

19. M. Fiorentino, D. Carriero, G. Laguardia, S. Manfreda, M.R. Margiotta, R. Rosano, A.Sole, V. Iacobellis, "Analyses on the spatial variability of hydrological losses during flood events", EGS-AGU-EUG Joint Assembly 2003, Nice, 2003.

20. R.B. Grayson, A.W. Western, F.H.S. Chiev, "Preferred states in spatial soil moisture patterns: local and nonlocal controls", Water Resources Research, 33(12), 2897-2908, 1997. 